\title{
Paradise Regained? Localised and Limited Nature Connexions in the UK's Covid-19 Lockdown
}

\author{
Julian Dobson ${ }^{1 * t}$, Tony Gore ${ }^{1 \dagger}$, Kim Graham ${ }^{2 \dagger}$ and Kate Swade ${ }^{2 \dagger}$ \\ ${ }^{1}$ Centre for Regional Economic and Social Research, Sheffield Hallam University, Sheffield, United Kingdom, ${ }^{2}$ Shared Assets \\ CIC, London, United Kingdom
}

Research has suggested that connexions between humans and the natural world lead to increased well-being and generate pro-environmental attitudes, which in turn benefit nature. This article asks whether users of outdoor public spaces in the UK during the Covid-19 pandemic in 2020 experienced greater connectedness with nature, consistent with the five "pathways to nature connectedness" identified in previous research. Semistructured interviews were conducted with a purposive sample of 42 individuals on their use of green and public spaces during the UK's lockdown, while a further 29 participants responded to an online survey. While the research revealed the importance of nature connectedness, only three of the five pathways were well-evidenced, and these connexions were frequently mediated by social activities. The article advances the study of nature connectedness by identifying challenges in applying the pathways framework and suggesting areas for further research to understand how the pathways operate in real-world conditions.

Middlesex University, United Kingdom Tenley M. Conway,

University of Toronto Mississauga,

Canada

${ }^{*}$ Correspondence:

Julian Dobson

julian.dobson@shu.ac.uk

†These authors have contributed equally to this work

Specialty section:

This article was submitted to Urban Resource Management, a section of the journal

Frontiers in Sustainable Cities

Received: 11 May 2021 Accepted: 30 November 2021 Published: 23 December 2021

Citation:

Dobson J, Gore T, Graham K and Swade K (2021) Paradise Regained? Localised and Limited Nature

Connexions in the UK's Covid-19

\section{INTRODUCTION}

The Covid-19 pandemic and the associated lockdowns in early 2020 prompted sudden shifts in public behaviour. Notable among these were changes in the use of public parks, green spaces such as woodlands and riversides, and public open spaces, both in the UK (Office for National Statistics, 2020a) and internationally. During the first phase of the pandemic, parks and green spaces were among the few public spaces that remained open in the UK. We refer to these henceforth as green and blue spaces (Geary et al., 2021).

The changes resulting from lockdown differed between locations and jurisdictions and at different stages of the pandemic, but an increased use of parks and green spaces was a common factor (Ugolini et al., 2020; Venter et al., 2020). In Chengdu, China, a survey with 386 respondents revealed that visiting green spaces "even once a week" during lockdowns could be beneficial (Xie et al., 2020). A further international survey (Pouso et al., 2021), with 5,218 respondents from nine countries, found that access to nature and "blue-green spaces" mitigated the deleterious mental health impacts of lockdowns. In the UK, the increased use of green and blue spaces contributed to a lively debate about their value, levels of public investment, and the continuing damage done by humans to the natural environment (Geary et al., 2021; Mell and Whitten, 2021).

Covid-19 thus generated a natural experiment (de Vocht et al., 2021) in public use of and engagement with green and blue spaces, in that it significantly changed familiar patterns of use, while leaving individuals able to engage in a variety of ways with the spaces that remained accessible. 
These forms of engagement are important because there is increasing awareness of the public health benefits of green and blue spaces, supported by extensive recent research. A range of reviews summarise and analyse this evidence base (World Health Organization, 2016; Houlden et al., 2018; Dobson et al., 2019; Hunter et al., 2019; Wendelboe-Nelson et al., 2019).

Among this research, there has been growing interest in the importance of "nature connectedness" or "nature relatedness" (Richardson and Sheffield, 2017) for mental health and wellbeing. Nature relatedness is defined as "a strong subjective connexion to nature" (Nisbet and Zelenski, 2013). Researchers have posited that if people experience a greater connexion with nature, they are more likely to take pro-ecological actions (Davis et al., 2011; Lumber et al., 2017). In this article we refer to "nature" rather than using alternative terms such as the "more-thanhuman" (Andrews, 2019) because it correlates to the concept of "nature connectedness"; we acknowledge that it is problematic in its tendency to characterise nature as "other" and reinforce the "nature-culture divide" (Braun, 2005).

This article draws on research on nature connectedness to explore how the lockdown both enabled and limited connexions with the natural world. We consider which types of space facilitated nature connectedness; how the lockdown reinforced the importance of nature for human well-being; and how the enjoyment of nature was restricted and unequally shared. Our examination of the evidence shows, as might be expected, that the lockdowns in the UK heightened participants' connexions with nature and afforded opportunities for new connexions. However, the circumstances of the lockdowns meant that such connexions were predominantly very local (often within walking or cycling distance) and therefore some connexions were no longer available to people. Nature connectedness was also constrained by the significantly increased use of some green and blue spaces, and by restrictions on social activities. Access to nature was also unequal, with many people-especially those without gardens, the clinically vulnerable and residents of more deprived neighbourhoods-unable to enjoy the natural world to the same extent as more privileged members of the public. This issue was observed by some participants in our research, but not directly experienced by them.

Lumber et al. (2017) propose five pathways to nature connectedness (discussed in more detail below): contact, beauty, emotion, meaning, and compassion. We examine which of these pathways were activated among users of green and blue spaces, and how this happened. Our analysis shows that connexions with nature during the lockdown were predominantly through contact (e.g., being in a green space); beauty (the aesthetic appreciation of the natural world); and emotion (the feelings prompted by experiences of nature). We consider these issues in more detail in our presentation of findings, analysis, and conclusions. Our study highlights the need for a better understanding not only of the pathways to nature connectedness but of the relationships between them, and the degree to which they are mediated by social activities and conditions.

This paper is based on an analysis of interview and survey material gathered between May and July 2020 from two research projects, both of which included an examination of the use of green and blue spaces in the UK during the initial lockdowns imposed to curb the spread of Covid-19. These data were re-examined to identify examples and types of nature connectedness. This analysis served two purposes: first, to categorise and understand the data generated from our research; and second, to examine in the light of real-world evidence the utility and applicability of the five pathways to nature connectedness, areas where further research is required, and potential applications to policy and practise.

We thus focus on two questions:

- How did the Covid-19 lockdowns affect participants' connexions with nature in green and blue spaces?

- How does the pathways to nature connexions framework enable us to understand how such connexions might influence behaviour change in the context of a climate and biodiversity emergency, and can it be adapted to real-world rather than experimental conditions?

\section{CONTEXT AND LITERATURE: GREEN SPACES AND NATURE CONNEXIONS}

Covid-19 offered a critical juncture (Schmidt, 2010): a moment at which behaviours and understandings are re-examined, with the potential to diverge from prior trajectories. The pandemic coincided with increasing public and political realisation of the impact of the climate and biodiversity crisis (Intergovernmental Science-Policy Platform on Biodiversity and Ecosystem Services (IBPES), 2019). This crisis had been brought to popular attention in the UK through the films of the naturalist David Attenborough, and raised up the political agenda, notably through the UK Government's 25 Year Environment Plan (HM Government, 2018), with its commitment to "environmental net gain" in development decisions, as well as the UK presidency of the COP26 climate summit in 2021 (United Nations, 2021).

In the UK, the initial period of the lockdown imposed to curb the spread of Covid-19 between 23 March and 4 July 2020 was characterised by the closure of most indoor facilities and, at first, a dramatic reduction in traffic, with private and commercial road traffic dipping to a low of $23 \%$ on 13 April compared with the previous year, before gradually increasing (Department for Transport, 2020). As the lockdown continued, weather improved and restrictions were gradually eased, there was a significant increase in the use of urban parks and public green spaces. While the overall proportion of the population using "public green and natural spaces" did not increase significantly during April 2020 (Office for National Statistics, 2020b), the ban on unnecessary travel resulted in a greater intensity of usage of urban green and blue spaces and a reduction in visits to national parks and countryside.

As mentioned above, there is a significant body of literature demonstrating the different ways in which access to, and time in, green spaces is conducive to improvements in health and well-being. A recent review of nearly 400 peer-reviewed studies published between 2009 and 2019 (Dobson et al., 2019) highlights the benefits associated with parks and urban green spaces, including supporting physical health and mental well-being; 
creating opportunities for social integration; and enabling people to connect with nature. Affordance theory (Gibson, 1979; Heft, 1988) underlines that the benefits of green spaces arise not from a process of causality but because green spaces generate opportunities, or affordances, for different forms of activity. A tree, for example, can be a site for children's play, a shady place to sit and enjoy a picnic or conversation, or can activate a sense of connexion with the wider natural world. It can be a place of discovery through watching birds or animals, or provide aesthetic pleasure as it changes through the seasons. Over time natural spaces can generate a sense of place attachment, a phenomenological state of "the bonding of people to places" (Low and Altman, 1992).

Nature connectedness can be an important aspect of such attachments to place, and attachments to particular places can amplify the links between nature connectedness and wellbeing (Basu et al., 2020). However, Gosling and Williams (2010) suggest that connecting with nature is more important than place attachment in driving pro-environmental behaviours. The theory of nature connectedness draws on the "biophilia hypothesis" (Wilson, 1984) which argues that humans have an innate need to connect with all living species because of their evolutionary beginnings. The natural world is thus a requirement for human health and development. Research has suggested that connexions between humans and the natural world lead to increased well-being (Howell et al., 2011; Pritchard et al., 2019; Duke and Soulsbury, 2021) and generate pro-environmental attitudes, which in turn benefit nature. Capaldi et al. (2015) link nature connectedness with both hedonic ("flourishing") and eudaemonic ("functioning") well-being. Nisbet and Zelenski (2013) report that " $[\mathrm{h}]$ igh nature relatedness, or a strong subjective connexion with nature, is typically associated with greater happiness and environmental concern." Davis et al. (2011) suggest that people who are "satisfied with and invested in the natural world" are more likely to act with the well-being of the natural environment in mind. Yang et al. (2018) found that people who experience "awe" at the natural world were more inclined to pro-ecological behaviours.

Research attention has recently been drawn to the practical application of the concept of nature connectedness to address what has been described as a need for "a new relationship with nature" (Richardson et al., 2020) in order to halt environmental destruction and reverse the negative relationships between humans and nature (Ison and Straw, 2020). To operationalise the application of nature connectedness, Lumber et al. (2017) devised the "pathways" framework, based on a series of experimental studies conducted at the University of Derby, UK. The studies formed an iterative process (described in detail in Lumber's article) of translating five of Kellert's nine domains of biophilia (Kellert, 1993) into five "pathways" by which humans experience and connect with the natural world. The pathways correspond to the types of relationship that best predict connectedness with nature (Table 1).

The framework has informed subsequent research designed to increase nature connectedness, including a study in which participants were encouraged to note "three good things" in nature for 5 days (Richardson and Sheffield, 2017); a large-scale public engagement campaign in which participants were invited to interact with nature for 30 days (Richardson and McEwan, 2018); and another using a smartphone app that encouraged urban residents to notice good things in nature (McEwan et al., 2019). Richardson et al. (2020) also provide examples of the operationalisation of the pathways into practise, though this evidence is self-reported rather than the subject of empirical research.

This paper complements existing research by seeking to understand how the pathways might be used as an analytical framework to understand real-world experiences, as opposed to data generated under experimental conditions. It aims to offer additional insights that can assist the development and operationalisation of the framework in practical situations. The Covid-19 lockdown provided an opportunity to apply the framework to analyse qualitative data about experiences of public spaces, including connexions with nature, generated through contemporaneous research. Our approach is outlined in the next section.

\section{METHODS}

This article considers data generated from two studies, each of which involved a series of interviews considering the use of public paces during the Covid-19 pandemic. Both projects were led by teams at the Centre for Regional Economic and Social Research (CRESR) at Sheffield Hallam University, and the lead authors of this article were involved in both projects. All the interviews took place in the summer of 2020.

Project 1 was an evaluation of Parks for People, a programme of investment in park improvements funded by two nongovernment bodies, The National Lottery Heritage Fund and The National Lottery Community Fund. As part of this evaluation, 21 members of the public in three locations were asked about their use during the pandemic of three parks where improvements had been funded through Parks for People. The three parks were in different locations: a low-income area in the east of Edinburgh, Scotland; Quorn, a village in Leicestershire in the English Midlands; and Tunbridge Wells, a commuter town south of London. Participants were recruited through snowball sampling initiated via local voluntary organisations, or volunteered to take part via an online survey that was part of the evaluation (survey respondents were contacted to check that they lived locally and/or used the parks being studied). Interviews were conducted by telephone or videoconferencing.

Project 2 was a scoping study on the health benefits of public spaces, with a particular focus on health inequalities, funded by a research charity, the Health Foundation. As part of this work 21 individuals with a range of professional expertise on green spaces, who had taken part in a policy forum at an earlier stage of the research, were interviewed about their own experiences of the lockdown and their awareness of the use of public spaces more generally during the pandemic. These interviewees worked for a variety of government departments, professional bodies, non-profit organisations and academic institutions. In addition, a short online survey covering a similar set of questions was 
TABLE 1 | Summative matrix of the pathways to nature connectedness and their corresponding biophilic values.

\begin{tabular}{|c|c|c|c|}
\hline Biophilic value & Definition & Pathway & Definition \\
\hline Naturalistic & Pleasure from contact with nature & Contact & The act of engaging with nature through the senses \\
\hline Aesthetic & Appeal of nature's physical beauty & Beauty & $\begin{array}{l}\text { The perception of aesthetic qualities including } \\
\text { shape, colour, and form that please the senses }\end{array}$ \\
\hline Symbolic & $\begin{array}{l}\text { Expressing ideas through nature based language } \\
\text { and metaphors }\end{array}$ & Meaning & $\begin{array}{l}\text { Using nature or natural symbolism to communicate } \\
\text { a concept that is not directly expressed }\end{array}$ \\
\hline Humanistic & Emotional bond with, and love for nature & Emotion & $\begin{array}{l}\text { An affective state or sensation that occurs as a } \\
\text { result of engaging with nature }\end{array}$ \\
\hline Moralistic & Ethical concern/judgements and revering nature & Compassion & $\begin{array}{l}\text { Extending the self to include nature, leading to a } \\
\text { concern for other natural entities that motivates } \\
\text { understanding and helping / co-operation }\end{array}$ \\
\hline
\end{tabular}

Source: Lumber et al. (2017, p. 19).

TABLE 2 | Data analysed to inform findings.

\begin{tabular}{llc}
\hline Type of data & Data source & N of participants \\
\hline Qualitative interviews (project 1) & Park users, Edinburgh & 6 \\
& Park users, Quorn & 5 \\
& Park users, Tunbridge Wells & 10 \\
Qualitative interviews (project 2) & Public space professionals & 21 \\
Survey respondents (project 2) & Online survey & 29 \\
Total & & 71 \\
\hline
\end{tabular}

conducted with a wider group of individuals $(N=42$, with 29 respondents) who had attended stakeholder consultations in three locations-Sheffield, Glasgow and London. These included members of local voluntary and community organisations concerned with the use and activation of public spaces.

Interviewees from Project 1 were aged between the mid-20s and 83 and included a mix of couples, families with children and single people. Demographic information was not collected in Project 2 as participants were selected on the basis of their professional or community activity. All the interviews were audio-recorded and transcribed verbatim, and the analysis is based primarily on these transcripts, plus the responses and freetext comments provided by participants in the online survey. Table 2 shows the location and type of interviews conducted for both research projects.

There were common themes in the questions asked of each group. These are shown in bold in Table 3. Both groups were asked about their experience of connexions with nature during the lockdown. Questions to both groups were based around four types of affordance offered by public open spaces: opportunities for physical activity; social activity; rest and relaxation; and connexions with nature. These are shown with illustrative examples in Table 4. The three groups of park users in Project 1 were only asked about their own experiences; the group involved in Project 2 were also asked for their more general views as professionals involved in the provision and use of public spaces. Respondents to the online survey were asked whether benefits of public spaces had increased or decreased during the Covid19 pandemic. They were questioned about four types of benefit, matching the four affordances in Table 4, and asked to rate their experience on a 5-point Likert scale (from "greatly reduced" to "greatly increased," with the addition of a "don't know" option). They applied this rating to four types of space in each category of affordance: green spaces, blue spaces, indoor spaces, and outdoor built spaces (such as streets or public squares). In addition, they were given the opportunity to provide free-text responses to each question.

\section{Approach to Analysis}

Our analysis takes a realistic rather than a theory-led approach (Pawson and Tilley, 1997), applying the framework retrospectively to data already generated rather than using the framework to generate the data. The questions we asked (Table 3) elicited information about which spaces participants had used and the activities they had engaged in, as well as the benefits they perceived from doing so. We hypothesised that if participants were connecting with nature, such connexions (and, by extension, the pathways to these connexions) would likely be revealed in their comments and recollections about how they were using public spaces and which activities they enjoyed.

We adopted an iterative approach to analysis, sharing the work between the article's authors in order to triangulate our understandings of the qualitative data and agree the central themes (Flick, 2007). First the lead author undertook a trial analysis of five of the 42 interview transcripts, using an open coding process to identify types of behaviour, types of spaces, and positive or negative experiences noted by research participants. These were then used to generate four tables categorising places where interviewees had experienced a connexion with nature, mapped against Lumber's five pathways; typologies of restrictions and limits on nature connectedness during the lockdown; numbers of participants experiencing probable (implied) or actual (explicitly stated) connexions to nature, mapped against the five pathways; and phrases used by participants to describe connexions with nature. All the transcripts were analysed using these tables as a starting point, sharing the work between the authors and then compiling and sense-checking the results. Additional categories were inserted where the data suggested gaps in the initial framework. Summary versions of the first three of these tables are included in the Findings section below as 
TABLE 3 | Interview questions for each research group (summarised).

\begin{tabular}{|c|c|c|}
\hline Topic focus & Project 1 questions & Project 2 questions \\
\hline Benefits of green spaces experienced by users & $\begin{array}{l}\text { Before } 23 \text { March, what activities did you take part in } \\
\text { at [name of park]? }\end{array}$ & \\
\hline Extent of use of green spaces & $\begin{array}{l}\text { Did you use any other parks or green spaces in your } \\
\text { area? }\end{array}$ & \\
\hline $\begin{array}{l}\text { Affordances of green spaces-matched against } \\
\text { categories in Table } 4\end{array}$ & Which activities did you enjoy most? & \\
\hline Impact of lockdown on use of space & $\begin{array}{l}\text { Since the lockdown, have you used local parks } \\
\text { and green spaces at all? }\end{array}$ & $\begin{array}{l}\text { Have you noticed any changes locally because } \\
\text { of COVID-19? Including those that differ from } \\
\text { national guidance (e.g., closure of parks or } \\
\text { footpaths)? }\end{array}$ \\
\hline $\begin{array}{l}\text { Continued benefits of green/public space during } \\
\text { lockdown (mapped against affordances) }\end{array}$ & $\begin{array}{l}\text { If you have been using green spaces, which } \\
\text { activities have you been able to continue? }\end{array}$ & $\begin{array}{l}\text { In what ways has COVID-19 highlighted the } \\
\text { health benefits of public spaces and enabled } \\
\text { people to access them? }\end{array}$ \\
\hline $\begin{array}{l}\text { Loss of benefits during lockdown (mapped } \\
\text { against affordances) }\end{array}$ & What have you had to stop doing? & $\begin{array}{l}\text { In what ways has COVID-19 limited the health } \\
\text { benefits of public spaces, including indoor } \\
\text { spaces? }\end{array}$ \\
\hline $\begin{array}{l}\text { Displacement effects - have users changed their } \\
\text { behaviours in response to lockdown? }\end{array}$ & & $\begin{array}{l}\text { In what ways have people been able to find alternative } \\
\text { ways of gaining these health benefits when their } \\
\text { regular spaces or venues have been closed? }\end{array}$ \\
\hline $\begin{array}{l}\text { Unexpected consequences of lockdown-have new } \\
\text { spaces become available? }\end{array}$ & & $\begin{array}{l}\text { Have people been able to take advantage of spaces } \\
\text { that are temporarily not being used in the usual way? }\end{array}$ \\
\hline
\end{tabular}

Themes common to both groups are in bold.

TABLE 4 | Types of space and affordances considered in interviews, with illustrative examples listed below each mode of activity (Research project 2).

\begin{tabular}{|c|c|c|c|c|}
\hline Types of space & Physical activity & Social activity & Relaxation \& rest & Connexions with nature \\
\hline Green space & Parkrun & Walking groups & Mindfulness, "forest bathing" & Wildlife observation \\
\hline Blue space & Wild swimming & Boating clubs & Fishing & Conservation volunteering \\
\hline Built space & Skateboarding & $\begin{array}{l}\text { Gatherings at community } \\
\text { hubs and centres }\end{array}$ & Use of libraries & $\begin{array}{l}\text { Community gardening, } \\
\text { appreciating street trees and } \\
\text { urban greening }\end{array}$ \\
\hline
\end{tabular}

Research Project 1 considered the same range of affordances, but only within the three green spaces that were the focus of attention.

Tables 5-7. After completing the analysis, the authors merged a number of categories in the first two tables where there were obvious overlaps.

In analysing the data, we extended the idea of "meaning" from Lumber's framework (Lumber et al., 2017: 19), where it is considered in terms of rhetoric and symbolism - "using nature or natural symbolism to communicate a concept that is not directly expressed." The data we considered, because they were concerned directly with experiences of natural or semi-natural places such as urban parks, did not lend themselves to the use of nature as a rhetorical device. We took the view that the nearest proxy within our material would be references to nature as shaping a participant's identity or worldview. Our working definition, therefore, is that meaning involves providing a sense of value to the individual, involving connectedness to the natural worldwhile acknowledging that such a definition overlaps with the "emotion" and "compassion" pathways.

Similarly, it was difficult to map our material directly onto the compassion pathway as defined by Lumber: "extending the self to include nature, leading to a concern for other natural entities that motivates understanding and helping/cooperation." Our research concerned people's experiences and feelings, rather than their conceptual understandings of their relations with the natural world. That said, it was evident that there were instances where participants expressed care and concern for the natural world, leading to acts of nurturing and tending. We note that the biophilic values that underpin Lumber's framework depict food growing as an example of a utilitarian attitude to the natural world. Our reading of participants' experiences of growing during the lockdown suggests that this is not necessarily the case: food growing can be evidence of a symbiotic and nurturing approach. We have therefore adapted our working definition of compassion to encompass a sense of care for the natural world, evidenced by activities to nurture or look after nonhuman species.

In substituting these definitions, we took the view that our understandings of participants' connectedness with nature should be driven by their self-reported actions and attitudes, rather than primarily by the theoretical framework. 
TABLE 5 | Places of nature connexion identified from interview data.

\begin{tabular}{|c|c|c|c|}
\hline Places of nature connexion (sorted by type) & $\begin{array}{l}\text { Probable (suggested } \\
\text { by interview material) } \\
\text { [n. of interviews } \\
\text { suggesting] }\end{array}$ & $\begin{array}{l}\text { Actual (specifically mentioned } \\
\text { by interviewee as connecting } \\
\text { with nature) [n. of interviews } \\
\text { mentioning] }\end{array}$ & Relevant pathways to nature connexion \\
\hline Parks and/or "green spaces" & 29 & 7 & Contact, beauty, emotion, compassion (care) \\
\hline "Blue spaces" including riversides, lakes, canals & 14 & 7 & Contact, beauty, emotion \\
\hline Private gardens & 12 & 3 & $\begin{array}{l}\text { Contact, beauty, emotion, meaning, } \\
\text { compassion (growing) }\end{array}$ \\
\hline $\begin{array}{l}\text { General local environment, public spaces, roads } \\
\text { (including derelict land) }\end{array}$ & 9 & 3 & Contact, beauty, emotion \\
\hline $\begin{array}{l}\text { Allotments, community gardens or orchards, gardening } \\
\text { projects }\end{array}$ & 7 & 4 & $\begin{array}{l}\text { Contact, beauty, compassion (food growing, } \\
\text { volunteering), meaning (ecology) }\end{array}$ \\
\hline Woodland, trees & 5 & 6 & Contact, beauty, emotion \\
\hline $\begin{array}{l}\text { Golf courses and other private spaces opened to the } \\
\text { public in lockdown }\end{array}$ & 10 & 0 & Contact \\
\hline Agricultural land, countryside (including cycle routes) & 5 & 0 & Contact \\
\hline Footpaths & 2 & 1 & Contact, beauty, compassion \\
\hline Tree/bird feeder outside flat & 0 & 2 & Contact, beauty, emotion (birdsong) \\
\hline Nature reserve & 2 & 0 & Contact, beauty, emotion \\
\hline Beaches & 2 & 0 & Contact \\
\hline City farms & 1 & 0 & Contact \\
\hline No connexions mentioned or implied & 0 & 0 & \\
\hline
\end{tabular}

\section{FINDINGS: SPACES OF AND PATHWAYS TO NATURE CONNEXIONS}

Our analysis suggests that connexions to nature were experienced in some types of places more than in others during the lockdown. The most commonly cited spaces were parks or places referred to generically as "green spaces"; this is not surprising, particularly as half the interviewees were users of particular parks. Six other types of space were consistently mentioned as sites of nature connexion, with probable or actual connexions identifiable in at least 10 cases (Table 5). "Blue" spaces, including streams, riversides, lakes and canals, were mentioned specifically as places to connect with nature in seven interviews and implied in 14 cases. Woodlands or trees were mentioned specifically six times and implied in five cases. Gardening projects, including community orchards, allotments and community gardens, were mentioned specifically by four respondents and implied in seven interviews as places to connect with nature. Private gardens were mentioned specifically three times and implied as sites of nature connexion in seven cases. The general local environment, including public spaces, streets and derelict land, were mentioned specifically as places to connect with nature three times, and implied in nine interviews.

One unexpected category was apparent in several interviews: golf courses. This is likely to be an anomaly resulting from the lockdown. In the UK, golf courses were closed for sport but many were either opened to the public for exercise or were appropriated as quasi-public green spaces because they were accessible.

Some types of space featured less than might be expected. Nature reserves were only mentioned by two respondents, possibly because many were closed or inaccessible because of travel restrictions; it is also possible that they may have been described by respondents as woodlands or green spaces rather than as nature reserves. City farms were almost all closed and were only mentioned by one participant. Similarly, only two mentioned beaches: the locations of our research were largely inland (Edinburgh was the exception) and travel restrictions would have prevented access to beaches except to local residents. There were no interviews where the participant did not mention or suggest any connexions with nature at all.

\section{Activating the Pathways to Nature Connexion}

It was clear from the interview material that the spaces mentioned enabled at least three of the pathways to nature connexions to be activated: contact, beauty and emotion. We found much less evidence of the two other pathways, meaning and compassion. As noted on page 5, we also found it difficult to correlate these two pathways with the self-reported experiences of participants in our research.

One example of contact with nature was described by a parent of a small child, who spoke of how her son instinctively engaged with the natural world in their local park: "he does like to run around and so I think he's just really enjoyed that there's more to do, and we found a tree that he can kind of climb in ... he's still quite little but he can still kind of climb in it and he loves picking up sticks and we've kind of just sat and looked for bugs in the grass." (Participant 30). Another interviewee spoke of exploring their local urban green spaces: "We've seen a kingfisher and we've seen loads of ducklings and goslings and a heron and an egret." (Participant 12). Another directly equated exploring with connecting with nature: "I think that bit around ecology, 
TABLE 6 | Limits on nature connexion identified from interview data.

\begin{tabular}{|c|c|c|}
\hline \multirow[t]{2}{*}{ Restrictions on nature connexion (by type) } & $\begin{array}{c}\text { Probable } \\
\text { (suggested } \\
\text { by interview } \\
\text { material) }\end{array}$ & $\begin{array}{c}\text { Actual } \\
\text { (specifically } \\
\text { mentioned as } \\
\text { preventing } \\
\text { nature } \\
\text { connexions) }\end{array}$ \\
\hline & $\begin{array}{c}\text { [n. of } \\
\text { interviews } \\
\text { mentioning/ } \\
\text { suggesting] }\end{array}$ & $\begin{array}{c}\text { [n. of } \\
\text { interviews } \\
\text { mentioning] }\end{array}$ \\
\hline $\begin{array}{l}\text { Cessation or closure of community } \\
\text { activities/facilities }\end{array}$ & 13 & 2 \\
\hline $\begin{array}{l}\text { Overcrowding/conflicts between } \\
\text { users/avoidance of constricted areas }\end{array}$ & 9 & \\
\hline Fear of antisocial behaviour & 8 & \\
\hline $\begin{array}{l}\text { Green spaces and play areas cordoned/fenced } \\
\text { off }\end{array}$ & 7 & \\
\hline $\begin{array}{l}\text { Unequal access to (quality) green space (e.g., } \\
\text { because of class, race, age, disability) }\end{array}$ & 7 & \\
\hline Closure of public toilets & 5 & 1 \\
\hline Restrictions on travel/closure of car parks & 4 & 3 \\
\hline Fear of/problems with dog mess & 4 & \\
\hline $\begin{array}{l}\text { Closure of entire green or outdoor spaces (e.g., } \\
\text { National Trust properties) }\end{array}$ & 4 & \\
\hline Lack of places to stop and sit/meet outdoors & 3 & \\
\hline Lack of access to private gardens & 2 & \\
\hline Shorter opening hours & 2 & \\
\hline Anxiety about leaving home & 1 & \\
\hline Notices discouraging use of parks & 1 & \\
\hline Lack of footpaths in countryside & 1 & \\
\hline
\end{tabular}

TABLE 7 | Number of interviews suggesting pathways to nature connectedness.

\begin{tabular}{lcc}
\hline Pathways to nature connexions & Probable & $\begin{array}{c}\text { Actual } \\
\text { (specifically } \\
\text { evidenced in } \\
\text { interview) } \\
\text { [n. of } \\
\text { interviews } \\
\text { mentioning] }\end{array}$ \\
\hline Contact & $\begin{array}{c}\text { [nterviews } \\
\text { suggesting] }\end{array}$ & 25 \\
Beauty & 12 & 17 \\
Meaning & 1 & 11 \\
Emotion & 11 & 2 \\
Compassion & 7 & 8 \\
\hline
\end{tabular}

particularly when we were only allowed out once a day, I think that made people investigate their local spaces a bit more, I think people have been trying to find where their local nature is." (Participant 19).

Beauty and aesthetic pleasure featured strongly in participants' descriptions of being outside. Participant 39 described the "fabulous" planting in their local park near a river, while Participant 10 commented on the pictures of spring flowers shared on social media. Participant 30 mentioned paying more attention to the trees in the local park: "for me, it was somewhere that I'd walk through quite quickly and not really notice anything whereas now, you know, we're looking at the trees and what kinds of trees they are..."

This pleasure and appreciation of natural beauty was often coupled with an emotional response. At times this could be described as a "cuteness factor," and several participants spoke of their joy at seeing ducklings, goslings and baby moorhens. But alongside this was a sense that being in the natural world enabled participants to handle the mental health challenges of the pandemic, which for many parents included the stress of having to homeschool for the first time. Participant 28 commented: “... it makes a big difference to both of my daughters... it's an anxious time for them, and they both definitely benefited mentally from being able to kind of go to the park, it's helped us all mentally."

Participant 29 linked the pleasure of being able to see ducklings and moorhens with a sense of relief at being outside in the natural world: "it was such a stressful time, you know, noone knew what was going on [...] Just to be able to actually have somewhere to go and you know, the ducks, there were ducklings and baby moorhens on the pond ... it just was so nice. Again, that whole nature thing, to get out and to actually be able to, you know, breathe and sort of, yes, just de-stress really by having somewhere that's nice to walk around."

Another talked about being able to "almost lose yourself in a wood": "I went for a walk last night which wasn't entirely through the park, but it took me into the park, you know, and felt just invigorated when I got back from that. And a lot of that was walking through the park and, you know, spending time looking at the trees, just absorbing things that I probably wouldn't normally notice." (Participant 26).

\section{Limits on Nature Connexion and the Importance of the Social}

We also asked participants about the restrictions on access to natural spaces they faced during the lockdown, and explored how these affected their connexions with nature. An important theme here is that the loss of social activities limits experiences of nature, but an excess of people can also impact on nature connexions. Table 6 shows the type of restrictions faced most frequently. While some respondents, unsurprisingly, mentioned the closure of particular green spaces and restrictions on travel as significant barriers to use, more talked about the closure of community facilities or cessation of activities such as volunteering in green spaces. One interviewee specifically mentioned the loss of volunteer-led nature walks: “... with nature walks and park groups, because they've had to stop, and volunteer groups and friends of park groups ... that aspect of being able to connect has had to stop" (Participant 15).

Outdoor organised activities, such as woodland maintenance in Grosvenor and Hilbert Park in Tunbridge Wells, ceased during the lockdown because they were not regarded as essential work and because of the risk of infection, aggravated by the vulnerability of many volunteers. Often volunteers are retirees or people with long-term physical or mental health problems that limit their ability to work full-time. 
While some were less able to connect with nature because the social activities that provided the occasion for engaging with nature ceased, others felt unable to connect because their local green spaces had become overcrowded and-in some casescharacterised by incidents of, or fears of, antisocial behaviour such as outdoor drinking and drug-taking. Typical comments included: "(It) has become so busy because of the lockdown ... so I can imagine it is quite difficult for people to get that nice, relaxing stroll" (Participant 18); and "When [teenagers] are bored, they hang around in groups, they can be quite intimidating" (Participant 38).

Another factor mentioned by interviewees-though usually without direct experience-was the impact of socioeconomic inequalities. Public access to green spaces in the UK, as in many other countries, is not equal, and even where there may be an equivalent amount of space per capita, the quality of that space tends to be poorer in more disadvantaged areas (Lee and Maheswaran, 2011; Brindley et al., 2019). The absence of private gardens also disproportionately affects people on low incomes, who may thus be doubly disadvantaged by having no access to private green space, and poorer quality public green and blue spaces. Long-term illnesses and mental health conditions are also more heavily concentrated in disadvantaged areas of England (Office for National Statistics, 2019), and many people with underlying health conditions were instructed to "shield" by staying at home entirely during the initial lockdown, preventing or severely constraining access to experiences of the natural world. As one greenspace professional told us: "Some of our projects we know provide a lifeline to people who already feel isolated and who are isolated because their health ... if somebody's genuinely anxious or fearful about coming out, as many are, then they potentially miss out on that benefit." (Participant 14). Even for those who could go out, sometimes the closure of public toilets created added anxiety and discomfort: one interviewee described this as "a major deterrent for certain groups of the population in using public spaces, particularly the elderly, others with certain health conditions, and also families with young children" (Participant 6).

In drawing conclusions from these data, we were conscious of the limitations of the sample size (42 interviews and 29 survey respondents). The sampling for both projects was purposive rather than representative. While we were made aware through our interviews of inequalities of access to and enjoyment of natural spaces during the lockdown, participants were not able to provide first-hand evidence. We therefore cannot comment from our data on whether nature connectedness is experienced differently by disadvantaged groups, although other recent research (Boyd et al., 2018; Birch et al., 2020) highlights the need to recognise the different ways in which people suffering disadvantage through race, age, mental health, and/or economic status connect with nature and construct meaning in their lives through such connexions.

\section{Additional Findings From Survey Responses}

The material from the 29 respondents to our online survey reinforced in general terms our findings of increased appreciation of or connectedness to nature during the lockdown, but tempered by limitations on access. Almost all of these respondents lived in the large UK cities where the consultations for the original research for Project 2 were held-Glasgow, Sheffield and London. The survey results revealed a mixed picture across all four affordances. Only in the case of health benefits associated with social activities was there an outright majority perceiving an overall reduction in benefit-supporting the findings from the qualitative material. For the other three affordances opinions were more divided; however, ten respondents said their connectedness to nature had increased in green spaces during the lockdown and 11 said it had greatly increased, while only four said it had reduced, three said it had greatly reduced, and one said there had been no change. Smaller numbers reported connectedness to nature within blue spaces-nine said it had increased or greatly increased, four reported no change, and ten said it had reduced or greatly reduced. Seven participants reported an increase in nature connectedness in outdoor built spaces, although nine reported a reduction and five said there had been no change.

Restrictions on nature connectedness evident from survey responses (based on free text comments) highlighted the impact of the closure of green spaces or play areas (10 instances); overcrowding or conflicts between users (four examples) and the closure of public toilets (two examples). There were also two comments suggesting that unequal access to green space was an issue, and one mentioning the cessation of community activities.

\section{Evidence of "Meaning" and "Compassion"}

While the connexions with nature evident from our data mapped strongly against the contact, beauty and emotion pathways, it was more difficult to evidence "meaning" and "compassion." This is significant because Lumber's work suggests that "enhanced contact with nature" (Lumber et al., 2017, p. 19), involving activities focused on emotion, meaning or compassion, result in greater nature connectedness than simply going for a walk in a natural environment. As discussed on page 5, we considered how we might extend Lumber's definitions and whether that might give us more insights into how these pathways were activated. In Table 7, which shows the instances of evidence for each pathway in our qualitative data, we include connexions that might fit a broader definition of meaning and compassion, but we offer these as exploratory rather than conclusive observations.

The data suggested several instances where, on these broader definitions of meaning and compassion, there was evidence that these pathways were activated during the Covid-19 lockdown. It was easier to identify instances of compassion than meaning, even using these broad definitions, and as Table 7 shows, the number of instances was much lower than for the other three pathways.

Examples of possible compassion include caring for plants and trees, either within parks (for example, in community orchards) or on allotment sites or in private gardens. One park user in Tunbridge Wells spoke of planting trees and returning to see how they were faring: "We planted some cherries and crab apples at the Upper Grosvenor Road entrance in February, so I've been up there a few times just to check 
they've settled in and so on" (Participant 23). It was noteworthy that this individual was already familiar with such activities through their prior involvement in volunteering at this parkin other words, there was a social element to the expression of compassion. Most of the other instances of compassion involved descriptions of volunteering activities in green spaces. One greenspace professional spoke more generally of a "shift in consciousness around environmental responsibility" perceived during the lockdown, but with the caveat that "we're all just trying to figure out if it's real or it's going to stick."

We noted examples of meaning when participants spoke about being in nature as informing a sense of self. One participant spoke of children enjoying connecting with nature in the outdoor environment of an allotment site:

"It's interesting, there always has been the Polish family that used to bring all their children down to their allotment, at least once a week, if not twice and they'd have a picnic up by the shed and they'd set up things to do ... and there are, oh ten, eleven families doing something very similar and the allotments are clearly a treat for people and a huge, hugely beneficial resource, not just for growing vegetables for a healthy diet, it's far, far wider than that and [for] children to learn ... there's a lot of lovely wild birds around and interesting butterflies, moths, insects, frogs, newts and the children are learning, interestingly, they love it." (Participant 25).

It is quite possible that examples of meaning and care existed more widely among participants, but were unstated because of the questions they were asked. However, especially in the case of meaning, this raises the issue of what form of research would be needed to identify such actions and attitudes within real-world, as opposed to experimental, contexts.

\section{DISCUSSION}

Our experience in applying the pathways to nature connectedness framework to empirical data raises a number of issues, which we consider here under four headings: (a) the utility of the pathways framework; (b) the extent and effects of nature connectedness during lockdown; (c) links between the pathways; and (d) the possible effects of the lockdown on nature connectedness and the importance of social activities.

\section{The Utility of the Pathways Framework}

We begin by acknowledging the value of the pathways framework in foregrounding the different routes to nature connectedness and the different impacts of these forms of connexion. However, our experience in attempting to retrofit the framework to existing empirical data highlights a gap between the clarity of theory and the messiness of practise. Even using the broader working definitions of "meaning" and "compassion" that we employed, it was difficult to demonstrate conclusively that participants in our research were constructing meanings or exercising compassion in their relationships with nature, although we consider this is probable in some cases. If it is only possible to demonstrate meaning and compassion under experimental conditions designed to elicit appropriate responses, such studies would carry a risk of confirmation bias.
Without a conclusive means of demonstrating the meaning and compassion pathways from the real-world evidence to hand, we are left with two contrasting sets of data. In the first case, there is clear evidence of the pathways of contact, emotion and beauty being activated among the participants we interviewed. In the second, there is the probability that in a small proportion of cases the pathways of meaning and compassion were activated, but additional research would be required to demonstrate this with any degree of certainty. Given that one of the values of the framework is to highlight the importance of meaning and compassion in reframing humans' relationship with the natural world, more thought may need to be given to how such pathways might be robustly demonstrated in practise. Further empirical research will be needed to explore this.

\section{Extent and Effects of Nature Connectedness}

Our research supports evidence (Robinson et al., 2021) that nature connectedness, and reliance on nature to support wellbeing, increased during lockdown. Among the participants in our research, there were links between nature connectedness and physical exercise (such as walking) and mental well-being (several spoke of relieving stress by being in natural environments or observing nature). The particular circumstances of the first lockdown in the UK, coinciding with a period of warm, bright spring weather, both created additional opportunities to observe and experience nature and-probably-increased the feelings of well-being associated with being outdoors. As one participant commented: ".. it does smell a bit nicer out there and maybe the colours seem a bit more vivid, but then it's May so of course the colours seem vivid cos it's not a gloomy day in November..." (Participant 9). The dramatic falls in traffic on urban streets during the first lockdown, referenced above, probably contributed to this heightened awareness of nature.

From our research it is not possible to evidence longerterm effects of this increased nature connectedness. None of our participants expressly said they would behave differently in future as a consequence of being more aware of the natural world. Had they done so, it would still be necessary to take account of the likely drop-off between expressed intentions and actual behaviour once the restrictions imposed during the pandemic are lifted. It is possible that the increased contact during the lockdown will have primed some participants in our research, and members of the public more widely, to engage with the natural world more often and more deeply, but longitudinal studies would be required to demonstrate this.

\section{Links Between the Pathways}

One reason for using the pathways framework in our analysis was to investigate whether there was any evidence of links between the pathways to nature connectedness. Could more time spent in the local park, for example, lead to more engagement in volunteering or supporting conservation organisations? Lumber et al. (2017, p. 19) suggest that "enhanced contact with nature" is needed to boost individuals' nature connexions. The short answer from this study is that no such development could be evidenced. Those who demonstrated care or compassion were largely those 
who were already involved in voluntary groups concerned with local green spaces, or were involved in the natural world in their professional capacities, or already grew food on allotment sites. This would suggest, in line with Lumber's findings, that activation of the more complex pathways of meaning and compassion are more likely to be associated with purposive activities-which suggests there is likely to be a social element to these pathways.

\section{Effects of Restrictions and the Importance of Social Activities}

The lockdown affected participants' use of outdoor spaces in four main ways, and these in turn had implications for their connexions with nature. A significant proportion (15 of 42 interviewees) were affected by the cessation of activities or closure of community facilities. Overcrowding of outdoor spaces or conflicts between different users affected nine participants, while eight were concerned about antisocial behaviour. Seven mentioned the closure of spaces such as play areas. Another seven were concerned about unequal access to green spaces, but it was notable that these inequalities were not experienced directly by participants.

Two contrasting themes emerge from the interview data. One is that connexions to nature are often experienced socially. Working alongside other volunteers in natural spaces, planting flowers, trees or vegetables in communal settings, or walking and observing the natural world with others, can be significant in activating the pathways to nature connectedness. For many of our participants, nature connectedness was entangled with connexions with other members of the human species.

The second theme, conversely, is that too many humans in one place can remove the sense of quiet and tranquillity that can also activate the pathways to nature connectedness. Participant 7 said that 'spaces which have perhaps been a bit busier are feeling quite threatening, people are feeling quite anxious going out there, [with] conflict between different users in terms of cyclists and runners on shared use paths and in very busy parks', while participant 18 spoke of using side streets rather than a waterside path because of the difficulty of maintaining a safe distance from others. An overriding concern with how others are using shared spaces and anxiety about personal safety (see, e.g., Arnberger and Brandenburg, 2007; Morris et al., 2011) is likely to reduce the benefits of contact with nature and close off the other pathways to nature connectedness. It is worth recalling that pioneers of public parks such as Frederick Law Olmsted envisaged them as "a cultural fix to the crowded and purportedly degenerative conditions of urban public spaces, tenement housing, and industrial workplaces" (Loughran, 2020).

\section{CONCLUSIONS}

Our research advances the study of nature connectedness in several ways. It shows that certain types of spaces are particularly important in people's experiences of nature connexions: woodlands and "blue" elements such as rivers and lakes, as well as gardens, were more strongly associated with nature connectedness. It also shows the importance of social connexions and conditions as mediators of nature connectedness. There was evidence, not all of it direct, that the limits on the organised use of and access to public spaces during the lockdown restricted opportunities to connect with nature, or potentially removed them for some groups. These social links may be particularly important in activating the pathways of meaning and compassion. Caring activities performed alongside others may reinforce individuals' sense of the value and significance of the natural world. Such activities were clearly limited during the Covid-19 pandemic. This is an area that needs further research, considering how different groups and communities experience nature connectedness through social and communal activities.

We found evidence that connexions with nature map strongly against three of the pathways in Lumber's framework-contact, beauty and emotion. We found that the definitions of meaning and compassion used in the framework made it difficult to trace connexions that may well have existed, and even when using broader definitions it was difficult to retrofit the interview data to the framework. Longer-term or ethnographic research-which was not possible in the context of Covid-19-could shed more light on this challenge.

While underlining that this analysis is exploratory, our conclusion is that more empirical testing of the pathways framework is required, particularly around the "meaning" and "compassion" pathways, in order to investigate how they can be activated and to ascertain whether a redefinition of these pathways might more accurately reflect people's experiences of connectedness to nature. Work is needed too to identify links and possible routes of progression between the pathways. Such studies will likely need to be longitudinal and cover a much longer period of time than the circumstances of early 2020. Our findings suggest that while the lockdown may have provided additional opportunities for many to connect with nature, there is not yet evidence that those connexions deepened to the extent that they activated new pathways to nature connectedness or resulted in changes in behaviour concomitant with the compassion pathway. While contact with nature may be a necessary condition to activate meaning and compassion, our evidence suggests it is not a sufficient condition. This raises the question of whether nature connectedness is, at least in part, socially generated.

A second conclusion is that our participants' experiences reveal a strong underlying connectedness to nature across all the groups we interviewed. Given the wide variety of uses of natural spaces (for social activities, exercise and sports, for example), the data suggest that the natural element of outdoor spaces is a significant factor in their use and appreciation. This reinforces the research on green spaces and well-being cited earlier, but also suggests that the design of public spaces should aim to highlight and increase the proportion and variety of natural or naturalistic features and "wild spaces" (Threlfall and Kendal, 2018).

Thirdly, our findings highlight the importance in urban policy and design of natural landscapes and features. Three factors stand out from our data. Spaces need to be accessible and diverse in order to provide multiple opportunities for people to connect with nature, and thought needs to be given to how to prevent overcrowding-for example, by offering a range of alternative 
routes to and through parks and green spaces. Our findings also reinforced the need for a variety of typologies of natural spaces to promote nature connectedness. Woodlands, watercourses, gardens and allotments were significant for our participants, suggesting that investment in parks and green spaces should focus on creating or preserving natural features and habitats and providing spaces where local residents can engage in planting and growing.

While work still needs to be done to investigate how the pathways to nature connectedness can be better activated, the experiences of participants in our research during the lockdown showed the benefits of enabling people to connect with nature in urban environments. To provide more opportunities for such connexions, urban planners and designers should consider a number of changes or improvements to current practises. These could include strengthening guidance on green spaces within new housing developments, including the provision of private and communal gardens; undertaking regular greenspace audits to test provision and accessibility against environmental justice criteria (Rigolon et al., 2018); green retrofitting to introduce natural habitats on streets, pathways and in vacant sites; and funding and support for community-led environmental and growing projects. The last of these may be particularly important, given the evidence we have found that connecting with nature is often a social and purposive activity.

\section{DATA AVAILABILITY STATEMENT}

The data analysed in this study are subject to the following licences/restrictions: The data analysed for this article form part of two larger datasets created for the two research projects cited in the article. These data are covered by GDPR

\section{REFERENCES}

Andrews, G. J. (2019). Health geographies II: the posthuman turn. Prog. Hum. Geogr. 43, 1109-1119. doi: 10.1177/0309132518805812

Arnberger, A., and Brandenburg, C. (2007). Past on-site experience, crowding perceptions, and use displacement of visitor groups to a peri-urban national park. Environ. Manage. 40, 34-45. doi: 10.1007/s00267-004-0355-8

Basu, M., Hashimoto, S., and Dasgupta, R. (2020). The mediating role of place attachment between nature connectedness and human well-being: perspectives from Japan. Sustain. Sci. 15, 849-862. doi: 10.1007/s11625-019-00765-x

Birch, J., Rishbeth, C., and Payne, S. R. (2020). Nature doesn't judge you - how urban nature supports young people's mental health and wellbeing in a diverse UK city. Health Place 62:102296. doi: 10.1016/j.healthplace.2020.102296

Boyd, F., White, M. P., Bell, S. L., and Burt, J. (2018). Who doesn't visit natural environments for recreation and why: a population representative analysis of spatial, individual and temporal factors among adults in England. Landsch. Urban Plan. 175, 102-113. doi: 10.1016/j.landurbplan.2018.03.016

Braun, B. (2005). Environmental issues: writing a more-than-human urban geography. Prog. Hum. Geogr. 29, 635-650. doi: 10.1191/0309132505ph574pr

Brindley, P., Cameron, R. W., Ersoy, E., Jorgensen, A., and Maheswaran, R. (2019). Is more always better? Exploring field survey and social media indicators of quality of urban greenspace, in relation to health. Urban Forestry Urban Greening 39, 45-54, doi: 10.1016/j.ufug.2019.01.015

Capaldi, C. A., Passmore, H.-A., Nisbet, E. K., Zelenski, J. M., and Dopko, R. L. (2015). Flourishing in nature: a review of the benefits of connecting with regulations in the UK and are held securely by Sheffield Hallam University. Requests to access these datasets should be directed to e.smith@shu.ac.uk.

\section{ETHICS STATEMENT}

The studies involving human participants were reviewed and approved by Emma Smith, Information Governance lead at the Centre for Regional Economic and Social Research, Sheffield Hallam University as part of the University's regular ethical approval process. The participants in both projects provided written informed consent to participate in this study.

\section{AUTHOR CONTRIBUTIONS}

All authors listed have made a substantial, direct, and intellectual contribution to the work and approved it for publication.

\section{FUNDING}

Project 1 was funded by the National Lottery Heritage Fund and the National Lottery Community Fund as part of a wider evaluation of their Parks for People programme. Project 2 was supported by the Health Foundation (Grant ID 1875030).

\section{ACKNOWLEDGMENTS}

The authors wish to acknowledge the contribution of Dr. Beth Speake, who contributed to the fieldwork in Project 1. nature and its application as a wellbeing intervention. Int. J. Wellbeing 5, 1-16. doi: 10.5502/ijw.v5i4.449

Davis, J. L., Le, B., and Coy, A. E. (2011). Building a model of commitment to the natural environment to predict ecological behavior and willingness to sacrifice. J. Environ. Psychol. 31, 257-265. doi: 10.1016/j.jenvp.2011. 01.004

de Vocht, F., Katikireddi, S. V., McQuire, C., Tilling, K., Hickman, M., and Craig, P. (2021). Conceptualising natural and quasi experiments in public health. $B M C$ Med. Res. Methodol. 21, 32-32. doi: 10.1186/s12874-021-01224-x

Department for Transport (2020). Transport Use During the Coronavirus (COVID-19) Pandemic. Official Statistics. Available online at: https://www.gov. $\mathrm{uk} /$ government/statistics/transport-use-during-the-coronavirus-covid-19pandemic

Dobson, J., Harris, C., Eadson, W., and Gore, T. (2019). Space to Thrive: A Rapid Evidence Review of the Benefits of Parks and Green Spaces for People and Communities. The National Lottery Heritage Fund and The National Lottery Community Fund, London.

Duke, L., and Soulsbury, C. D. (2021). Human-wildlife interaction networks at urban blue spaces. Area 53, 122-133. doi: 10.1111/area.12683

Flick, U. (2007). Managing Quality in Qualitative Research. London: SAGE Publications. doi: 10.4135/9781849209441

Geary, R. S., Wheeler, B., Lovell, R., Jepson, R., Hunter, R., and Rodgers, S. (2021). A call to action: Improving urban green spaces to reduce health inequalities exacerbated by COVID-19. Prev. Med. 145, 106425-106425. doi: 10.1016/j.ypmed.2021.106425 
Gibson, J. (1979). The Ecological Approach to Visual Perception. London: Lawrence Erlbaum.

Gosling, E., and Williams, K. J. (2010). Connectedness to nature, place attachment and conservation behaviour: testing connectedness theory among farmers. J. Environ. Psychol. 30, 298-304. doi: 10.1016/j.jenvp.2010. 01.005

Heft, H. (1988). Affordances of children's environments: a functional approach to environmental description. Child. Environ. Q. 5, 29-37.

HM Government (2018). A Green Future: Our 25 Year Plan to Improve the Environment. London: Defra. Available online at: https://assets.publishing. service.gov.uk/government/uploads/system/uploads/attachment_data/file/ 693158/25-year-environment-plan.pdf

Houlden, V., Weich, S., Porto de Albuquerque, J., Jarvis, S., and Rees, K. (2018). The relationship between greenspace and the mental wellbeing of adults: a systematic review. PLoS ONE 13:e0203000-e0203000. doi: 10.1371/journal.pone. 0203000

Howell, A. J., Dopko, R. L., Passmore, H.-A., and Buro, K. (2011). Nature connectedness: associations with well-being and mindfulness. Pers. Individ. Dif. 51, 166-171. doi: 10.1016/j.paid.2011. 03.037

Hunter, R., Cleland, C., Cleary, A., Droomers, M., Wheeler, B., Sinnett, D., et al. (2019). Environmental, health, wellbeing, social and equity effects of urban green space interventions: a meta-narrative evidence synthesis. Environ. Int. 130, 104923-104923. doi: 10.1016/j.envint.2019. 104923

Intergovernmental Science-Policy Platform on Biodiversity and Ecosystem Services (IBPES) (2019). Global Assessment Report on Biodiversity and Ecosystem Services. Bonn, Germany. Available online at: https://www.ipbes.net/ news/Media-Release-Global-Assessment

Ison, R., and Straw, E. (2020). The Hidden Power of Systems Thinking: Governance in a Climate Emergency. Abingdon: Routledge. doi: 10.4324/978135102 6901

Kellert, S. R. (1993). "The biological basis for human values of nature," in The Biophilia Hypothesis, eds S. R. Kellert and E. O. Wilson (Washington, DC: Island Press), 42-69.

Lee, A. C. K., and Maheswaran, R. (2011). The health benefits of urban green spaces: a review of the evidence. J. Public Health 33, 212-222. doi: 10.1093/pubmed/fdq068

Loughran, K. (2020). Urban parks and urban problems: An historical perspective on green space development as a cultural fix. Urban Stud. 57, 2321-2338. doi: $10.1177 / 0042098018763555$

Low, S., and Altman, I. (1992). "Place attachment," in Place Attachment, eds I. Altman, and S. Low (New York, NY: Springer US), 1-12. doi: 10.1007/978-1-4684-8753-4_1

Lumber, R., Richardson, M., and Sheffield, D. (2017). Beyond knowing nature: Contact, emotion, compassion, meaning, and beauty are pathways to nature connection. PLoS ONE 12:e0177186. doi: 10.1371/journal.pone. 0177186

McEwan, K., Richardson, M., Sheffield, D., Ferguson, F. J., and Brindley, P. (2019). A smartphone app for improving mental health through connecting with urban nature. Int. J. Environ. Res. Public Health. 16:3373. doi: 10.3390/ijerph161 83373

Mell, I., and Whitten, M. (2021). Access to nature in a post Covid-19 world: opportunities for green infrastructure financing, distribution and equitability in urban planning. Int. J. Environ. Res. Public Health 18, 1527-. doi: $10.3390 /$ ijerph 18041527

Morris, J., O'Brien, E., Ambrose-Oji, B., Lawrence, A., Carter, C., and Peace, A. (2011). Access for all? Barriers to accessing woodlands and forests in Britain. Local Environ. 16, 375-396. doi: 10.1080/13549839.2011. 576662

Nisbet, E. K., and Zelenski, J. M. (2013). The NR-6: a new brief measure of nature relatedness. Front. Psychol. 4, 813-813. doi: 10.3389/fpsyg.2013. 00813

Office for National Statistics (2019). English Indices of Deprivation 2019. Available online at: https://www.gov.uk/government/statistics/english-indicesof-deprivation-2019

Office for National Statistics (2020a). People and Nature Survey for England: Monthly interim indicators for September 2020 (Experimental
Statistics). Available online at: https://www.gov.uk/government/publications/ the-people-and-nature-survey-for-england-monthly-interim-indicatorsfor-september-2020-experimental-statistics/the-people-and-nature-surveyfor-england-monthly-interim-indicators-for-september-2020-experimentalstatistics

Office for National Statistics (2020b). People and Nature Survey for England: Monthly Interim Indicators for April 2020 (Experimental Statistics). Available online at: https://www.gov.uk/government/statistics/the-people-andnature-survey-for-england-monthly-interim-indicators-for-april-2020experimental-statistics

Pawson, R., and Tilley, N. (1997). Realistic Evaluation. Thousand Oaks: SAGE.

Pouso, S., Borja, Á., Fleming, L. E., Gómez-Baggethun, E., White, M. P., and Uyarra, M. C. (2021). Contact with blue-green spaces during the COVID19 pandemic lockdown beneficial for mental health. Sci. Total Environ. 756, 143984-143984. doi: 10.1016/j.scitotenv.2020.143984

Pritchard, A., Richardson, M., Sheffield, D., and McEwan, K. (2019). The relationship between nature connectedness and eudaimonic wellbeing: a meta-analysis. J. Happiness Stud. 21, 1145-1167. doi: 10.1007/s10902-01900118-6

Richardson, M., Dobson, J., Abson, D. J., Lumber, R., Hunt, A., Young, R., et al. (2020). Applying the pathways to nature connectedness at a societal scale: a leverage points perspective, Ecosyst. People 16, 387-401. doi: $10.1080 / 26395916.2020 .1844296$

Richardson, M., and McEwan, K. (2018). 30 days wild and the relationships between engagement with nature's beauty, nature connectedness and well-being. Front. Psychol. 9:1500. doi: 10.3389/fpsyg.2018. 01500

Richardson, M., and Sheffield, D. (2017). Three good things in nature: noticing nearby nature brings sustained increases in connection with nature/Tres cosas buenas de la naturaleza: prestar atención a la naturaleza cercana produce incrementos prolongados en conexión con la naturaleza. Psyecology 8, 1-32. doi: $10.1080 / 21711976.2016 .1267136$

Rigolon, A., Browning, M., and Jennings, V. (2018). Inequities in the quality of urban park systems: an environmental justice investigation of cities in the United States. Landsch. Urban Plan. 178, 156-169. doi: 10.1016/j.landurbplan.2018.05.026

Robinson, J. M., Brindley, P., Cameron, R., MacCarthy, D., and Jorgensen, A. (2021). Nature's role in supporting health during the COVID-19 pandemic: a geospatial and socioecological study. Int. J. Environ. Res. Public Health 18, 2227. doi: 10.3390/ijerph18052227

Schmidt, V. A. (2010). Taking ideas and discourse seriously: explaining change through discursive institutionalism as the fourth "new institutionalism." Eur. Polit. Sci. Rev. 2, 1-25. doi: 10.1017/S175577390999021X

Threlfall, C. G., and Kendal, D. (2018). The distinct ecological and social roles that wild spaces play in urban ecosystems. Urban For. Urban Greening 29, 348-356. doi: 10.1016/j.ufug.2017.05.012

Ugolini, F., Massetti, L., Calaza-Martínez, P., Cariñanos, P., Dobbs, C., Ostoić, S. K., et al. (2020). Effects of the COVID-19 pandemic on the use and perceptions of urban green space: an international exploratory study. Urban Greening 56, 126888-126888. doi: 10.1016/j.ufug.2020.126888

United Nations (2021). UN Climate Change Conference UK 2021. Available online at: https://ukcop26.org

Venter, Z. S., Barton, D. N., Gundersen, V., Figari, H., and Nowell, M. (2020). Urban nature in a time of crisis: Recreational use of green space increases during the COVID-19 outbreak in Oslo, Norway. Environ. Res. Lett. 15. doi: 10.1088/1748-9326/abb396

Wendelboe-Nelson, C., Kelly, S., Kennedy, M., and Cherrie, J. W. (2019). A scoping review mapping research on green space and associated mental health Benefits. Int. J. Environ. Res. Public Health 16, 1-49. doi: 10.3390/ijerph161 22081

Wilson, E. O. (1984). Biophilia. Cambridge: Harvard University Press.

World Health Organization (2016). Urban Green Spaces and Health: A Review of Evidence. Copenhagen: WHO Regional Office for Europe. Available online at: http://www.euro.who.int/_data/assets/pdf_file/0005/321971/Urbangreen-spaces-and-health-review-evidence.pdf?ua $=1$

Xie, J., Luo, S., Furuya, K., and Sun, D. (2020). Urban parks as green buffers during the COVID-19 pandemic. Sustainability (Switzerland), 12:6751. doi: 10.3390/SU12176751 
Yang, Y., Hu, J., Jing, F., and Nguyen, B. (2018). From awe to ecological behavior: the mediating role of connectedness to nature. Sustain. 10, 2477. doi: $10.3390 /$ su10072477

Conflict of Interest: The authors declare that the research was conducted in the absence of any commercial or financial relationships that could be construed as a potential conflict of interest.

Publisher's Note: All claims expressed in this article are solely those of the authors and do not necessarily represent those of their affiliated organizations, or those of the publisher, the editors and the reviewers. Any product that may be evaluated in this article, or claim that may be made by its manufacturer, is not guaranteed or endorsed by the publisher.

Copyright (C) 2021 Dobson, Gore, Graham and Swade. This is an open-access article distributed under the terms of the Creative Commons Attribution License (CC BY). The use, distribution or reproduction in other forums is permitted, provided the original author(s) and the copyright owner(s) are credited and that the original publication in this journal is cited, in accordance with accepted academic practice. No use, distribution or reproduction is permitted which does not comply with these terms. 